\title{
Clinical and laboratory features of seven patients with acute myeloid leukemia (AML)-M2/M3 and elevated myeloblasts and abnormal promyelocytes
}

GanLin He ${ }^{1}$, ChunYan Wang ${ }^{1 *}$, QingEn Li ${ }^{1}$, Huo Tan ${ }^{1 *}$, FuXiong Chen ${ }^{2}$, ZhenQian Huang ${ }^{1}$, BaoDan Yu ${ }^{3}$, LiXia Zheng ${ }^{3}$, RunHui Zheng ${ }^{1}$ and Dan Liu'

\begin{abstract}
Background: There is limited information on a special subtype of Acute myeloid leukemia (AML) characterized by $>20 \%$ myeloblasts and $>20 \%$ abnormal promyelocytes in bone marrow and peripheral blood.

Objective: The objective of the present investigation was to explore the clinical and laboratory features of seven patients with AML-M2/M3.

Method: We retrospectively assessed cell morphology, cytochemistry, immunophenotype, cytogenetics, and clinical features of seven patients with this rare subtype of AML.

Results: All seven cases had thrombocytopenia, coagulation abnormalities, $>20 \%$ myeloblasts and abnormal promyelocytes. The PML/RARa fusion gene was present in six patients and two patients presented a mixed PML/ RARa and AML1/ETO genotype. Five cases achieved CR and two cases did not achieve remission and one case transform into AML-M2 after $\mathrm{CR}_{1}$.

Conclusions: The clinical and laboratory features of seven patients with AML-M2/M3 are demonstrated in the present study, providing information on the FAB sub-classification.
\end{abstract}

Keywords: Acute myeloid leukemia (AML), AML-M2/M3 subtype, Mixed phenotype, Myeloblasts, Abnormal promyelocytes

\section{Background}

Acute myeloid leukemia (AML) is characterized by clonal expansion of myeloid blasts in bone marrow (BM), peripheral blood $(\mathrm{PB})$, or other tissues. In the World Health Organization (WHO) scheme (2008), a myeloid neoplasm with $20 \%$ or more myeloblasts in the PB or BM is considered to be AML. Acute myeloid leukemia with the gene rearrangement $\mathrm{t}(8 ; 21)$ (q22; q22); (AML1/ETO), which is also referred to as the RUNX1 gene, and AML with the rearrangement $t(15 ; 17)(\mathrm{q} 22 ; \mathrm{q} 12)(\mathrm{PML} / \mathrm{RAR} \alpha)$ are considered distinct AML subtypes. In the FrenchAmerican-British (FAB) classification scheme for AML, the criteria for AML-M2 is $30 \%$ to $89 \%$ myeloblasts, $>10 \%$

\footnotetext{
*Correspondence: wcy163@163.com; tanhuo.2008@163.com

'Department of Hematology, The First Affiliated Hospital of Guangzhou Medical University, No. 1 Kangda Road, Haizhu District, 510000 Guangzhou, China

Full list of author information is available at the end of the article
}

promyelocytes and neutrophilic myelocyte, and $<20 \%$ monocytes [1-9].

Two cases of AML with simultaneous PML/RARa and AML1/ETO gene rearrangement have been reported [10]. We have encountered seven cases with myeloblast fractions ranging from $36-85 \%$ and a fraction of abnormal promyelocytes from $24-49.5 \%$, with one patient presenting with simultaneous AML1/ETO and PML/RAR $\alpha$ fusion genes [11-18]. In this paper, we retrospectively analyze all seven cases diagnosed as AML-M2/M3, to present a general picture of the clinical symptoms, laboratory results, prognosis, and treatment responses of this unusual AML subtype.

\section{Materials and methods}

\section{Clinical information}

The current study was approved by the Department of Hematology of the First Affiliated Hospital of Guangzhou

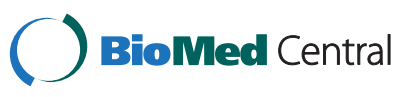


Medical University. Patients were enrolled and treated from Jan. 2008 to Jun. 2012. Study eligibility criteria included availability of bone marrow histology and cytogenetic information at the time of referral to the Department of Hematology. Acute myeloid leukemia was diagnosed according to the World Health Organization criteria $[1,2,8]$. During the study period, seven patients, aged 8 to 76 , were newly diagnosed with AML-M2/M3 based on $>30 \%$ myeloblasts and $>20 \%$ abnormal promyelocytes as well as predominant myeloperoxidase (MPO or POX) and naphthol AS-D chloroacetate esterase (AS-DCE, or specific esterase, $\mathrm{SE}$ ) positive status. Bone marrow smears, $\mathrm{PB}$ smears, and detailed morphological, immunochemical, and cytogenetic analyses of BM biopsy tissue were conducted for each patient. The myeloid lineage was assessed using antibodies against CD9, CD11b, CD13, CD15, CD33, CD34, CD38, CD45, CD56, CD64, CD117, HLA$\mathrm{DR}$, and $\mathrm{cMPO}$. The lymphocyte $\mathrm{T}$ cell lineage was assessed using antibodies against CD2, CD3, CD5 and $\mathrm{CD} 7$, while the $\mathrm{B}$ cell lineage was assessed using antibodies against CD19, CD20, CD22, and CD79a.

\section{Flow cytometry}

The flow cytometer of COULTER EPICS XL type with $488 \mathrm{~nm}$ excitation light source was used in the present investigation, and System II software was employed for analysis. After calibration with Fluorescent Microspheres and adjustment Fluorescence compensation of the machine, three-color fluorescent staining of the same type sample was done to serve as negative control to exclude nonspecific fluorescence staining. According to the degree of expression of CD45 and particle size of SSC, the cells were divided into granulocytes, monocytes, lymphocytes, immature lymphocyte populations and immature myeloid cells group, red blood cells and debris cells. After analysis of each cell group, naive cells were determined. The expression of antigen was analyzed by two-dimensional phenotypic spectrum.

\section{Case studies}

Case 1: A 10-year-old male presented with fever

Bone marrow smears showed hyperactivity of the myeloid lineage; myeloblasts and abnormal promyelocytes together comprised $100 \%$ of the BM cells. Abnormal promyelocytes, but with no Auer rods, accounted for $38 \%$ of all cells. Some myeloblasts exhibited one or two prominent nucleoli. Results of immunohistochemistry of BM biopsy tissue were consistent with AML: $\mathrm{MPO}(+++), \mathrm{CD} 117(+++)$, TdT(-), CD34(-), L26(-), UCHL-1(+),CD3(-), CD79a partial $(+), \mathrm{Fe}(-)$, and reticular fiber(-) (Figure 1).

Case 2: A 57-year-old male presented with vertigo, pale and fever

Bone marrow smears revealed hyperactivity of the myeloid lineage. Results of a BM biopsy were consistent with
AML. Most AML cells were MPO (+), CD20 partial (+), CD79a partial (+), CD3 partial (+), some CD138 (+), CD4 $(-), \mathrm{CD} 5(-), \mathrm{Ag}(+)$, and Fe (-).

\section{Case 3: A 57-year-old female presented with mucocutaneous} hemorrhage and fever

In BM smears, the myeloid lineage was hyperactive, with $39.5 \%$ myeloblasts and $49 \%$ abnormal promyelocytes.

\section{Case 4: A 32-year-old male presented with fever and mucocutaneous hemorrhage}

Results of BM biopsy were consistent with AML: MPO (+), CD117(+), LCA(+), Ki-67 approximately 20\%(+), CD3 (-), CD34(-),TdT(-), CK(-), Ag(++), and Fe(-).

\section{Cases 5: A 76-year-old male presented with dizziness}

Bone marrow smears revealed $42.5 \%$ myeloblasts and $30 \%$ abnormal promyelocytes. Cytochemistry indicated 99\% MPO (+) cells. Most cells also appeared AS-DCE $(+)$. The immunophenotype was MPO (+), CD117 (+), LCA (+), about 20\% Ki-67(+), CD3 (-), CD34 (-), TdT $(-)$, CK (-), Ag $(++)$, and Fe (-). Cytogenetic analysis indicated the presence of the PML/RARa fusion gene, $\mathrm{S}$ type. Immunophenotyping by FCM revealed that $76.4 \%$ of BM karyocytes were abnormal (group C, red). Most cells were weakly CD45 (+), while $30.9 \%$ were CD13 (+) 11.6\% CD15 (+), 95.5\% CD33 (+), 96.5\% CD56 (+), 16.9\% CD64 (+), 78.4\% CD117 (+), and 84.3\% were positive for the cytoplasmic antigen of cMPO. Cells were negative for antigens of the lymphocytic lineage (Figure 2).

\section{Case 6: An 8-year-old male presented with rashes}

Bone marrow smears revealed $17 \%$ myeloblasts and 49.5\% abnormal promyelocytes. Peripheral blood smears consisted of $36 \%$ myeloblasts and $28 \%$ promyelocytes. Cells were positive for the PML/RARa fusion gene, $\mathrm{S}$ type, and the AML1/ETO fusion gene. The immunophenotype by FCM was approximately $44.9 \%$ bone marrow blast cells. Within this population, $29.6 \%$ were CD34/HLA-DR (+), 6.5\% CD15 (+), 0.2\% CD14/CD11b (+), and 3.5\% HLA-DR/CD13 (+). No antigens of the lymphocytic lineage were detected.

\section{Case 7: A 30-year-old female presented with bone pain and fever}

Bone marrow smears revealed 49\% myeloblasts and 13\% abnormal promyelocytes, while the cells in the PB smear were $14 \%$ myeloblasts and $13 \%$ promyelocytes. The BM cells harbored both the PML/RARa fusion gene, S type, and the AML1/ETO fusion gene. Immunophenotyping by FCM revealed two groups of blast cells. The SSC lower cell group was approximately $44.9 \%$ of the total and this population was $13.5 \% \mathrm{CD} 11 \mathrm{~b}(+), 90.8 \% \mathrm{CD} 13$ 


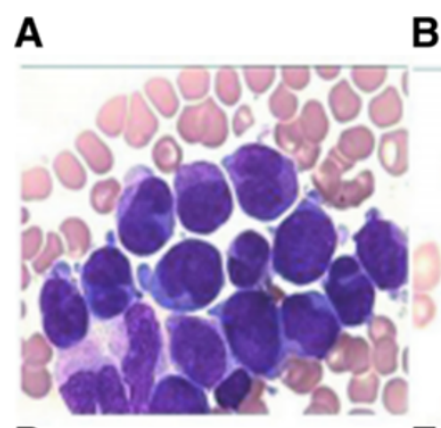

D

E

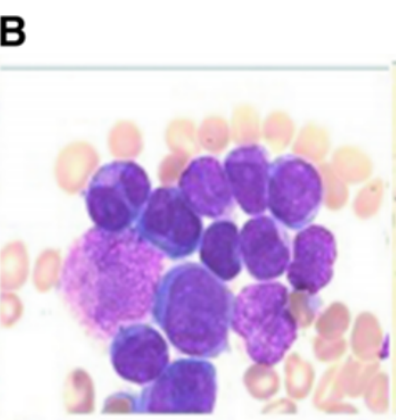

C

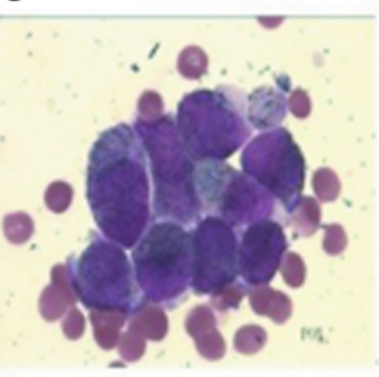

F
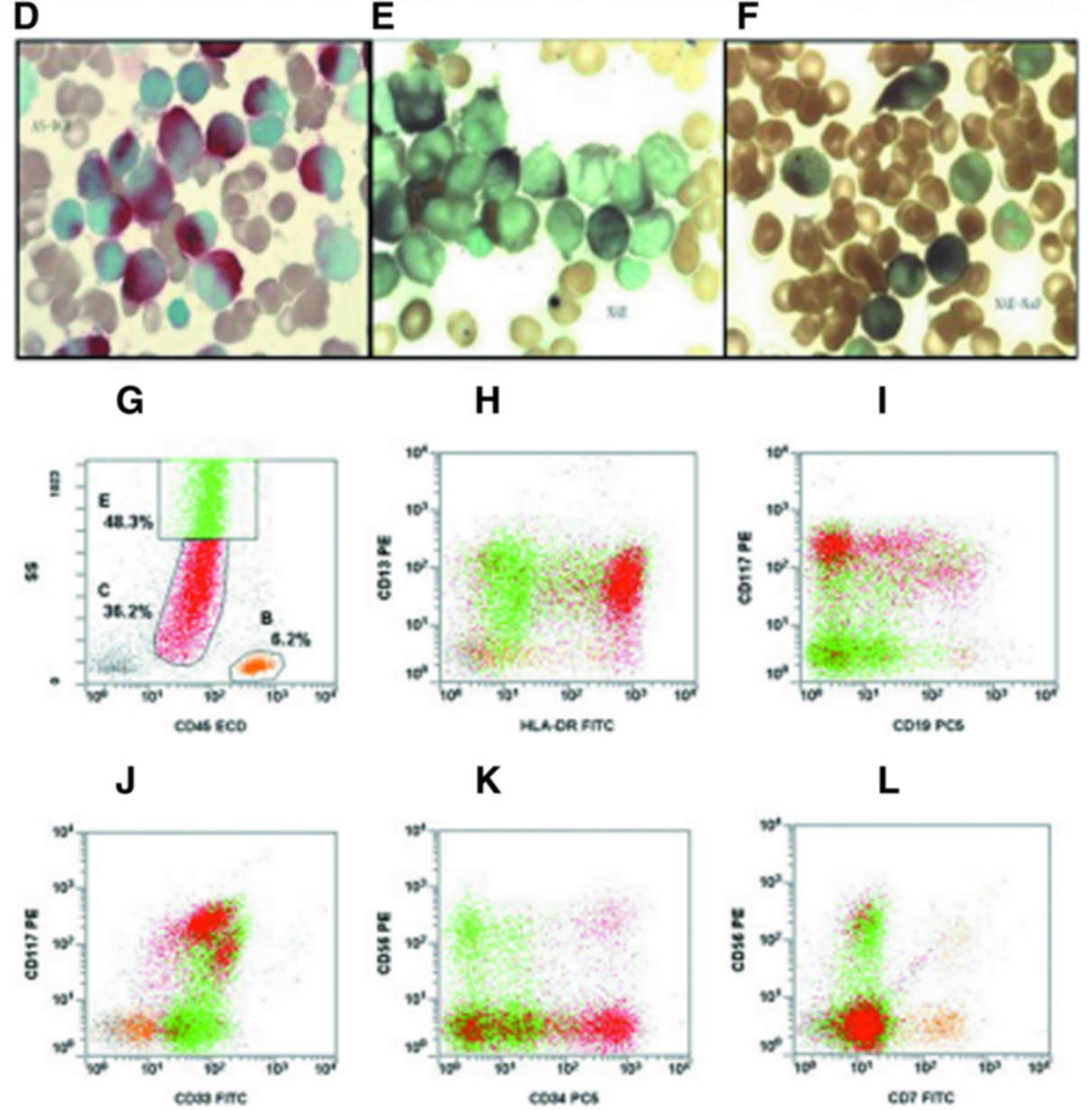

.
H

J

G

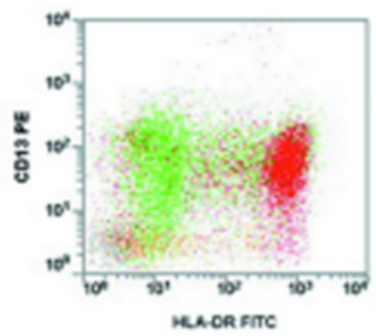

K

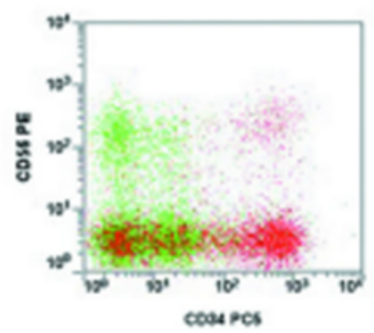

I

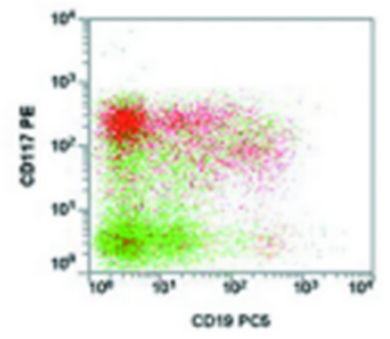

L

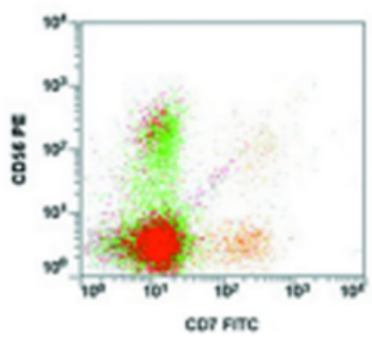

Figure 1 Morphological and immunological characteristics of BM cells in AML-M2/M3 patients. A, B: Bone marrow smears demonstrated hyperplasia of the myeloid lineage. Myeloblasts and abnormal promyelocytes accounted for $>30 \%$ of BM cells. Abnormal promyelocytes were round, oval, or elliptical. The cytoplasm contained intense dust-like azurophilic granulation and some abnormal promyelocytes contained Auer rods. The nuclear size and shape were irregular; the nucleus could either appear kidney-shape, cerebriform, or even bi-lobed, with inconspicuous to prominent nucleoli. C: MPO: 99\% positive; D: AS-DCE: 70\% positive; E: NSE: particle positive; $\mathbf{F}$ : NSE positive cells were inhibited by NaF. G-L: Immunophenotype as determined by FCM for Case 7 showing two distinct groups of blast cells (red and green).

(+), 40.3\% CD15(+), 82.6\% CD33(+), 62.3\% CD34(+), $12.4 \%$ CD56(+), $40.3 \%$ CD64(+), $88.0 \%$ CD117(+), $85.9 \%$ HLA-DR (+), and $97.8 \% \mathrm{cMPO}(+)$, while no antigens of other lineages were expressed. The SSC lower cell group was approximately $48.3 \%$ of the total and this population was $46.6 \% \mathrm{CD} 11 \mathrm{~b}(+), 94.9 \% \mathrm{CD} 13(+), 17.3 \% \mathrm{CD} 14(+)$, 95.3\% CD15(+), 83.0\% CD33(+), 26.1\%(+) CD56, 70.4\%
CD64(+), 43.8\% CD117(+), 35.0\% HLA-DR(+), and 98.9\% $\mathrm{cMPO}(+)$. Antigens of other lineages were not expressed (Figure 3).

Patients' clinical profiles, the proportions of myeloblasts and abnormal promyelocytes in BM and PB smears, immunocytochemical determination of $\mathrm{MPO}(+)$ and AS-DCE(+) fractions, results of immunophenotyping 

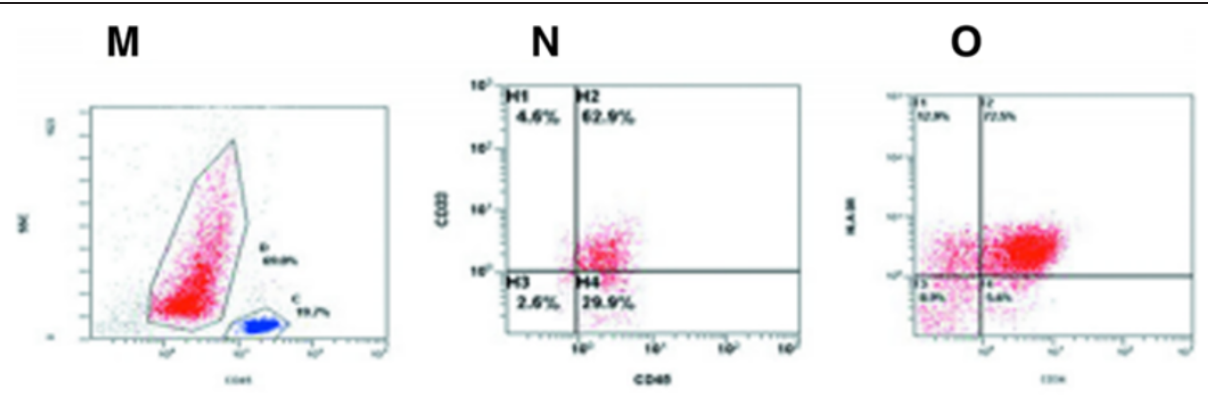

$\mathbf{P}$

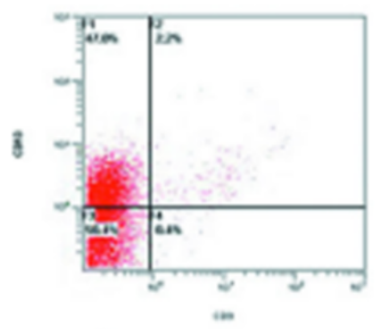

Q

$\mathbf{R}$
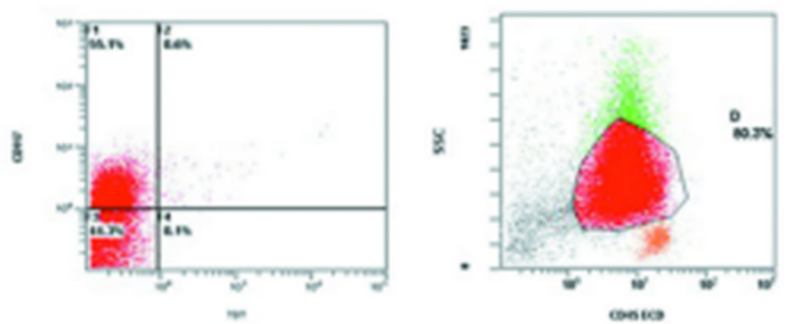

S

$\mathbf{T}$
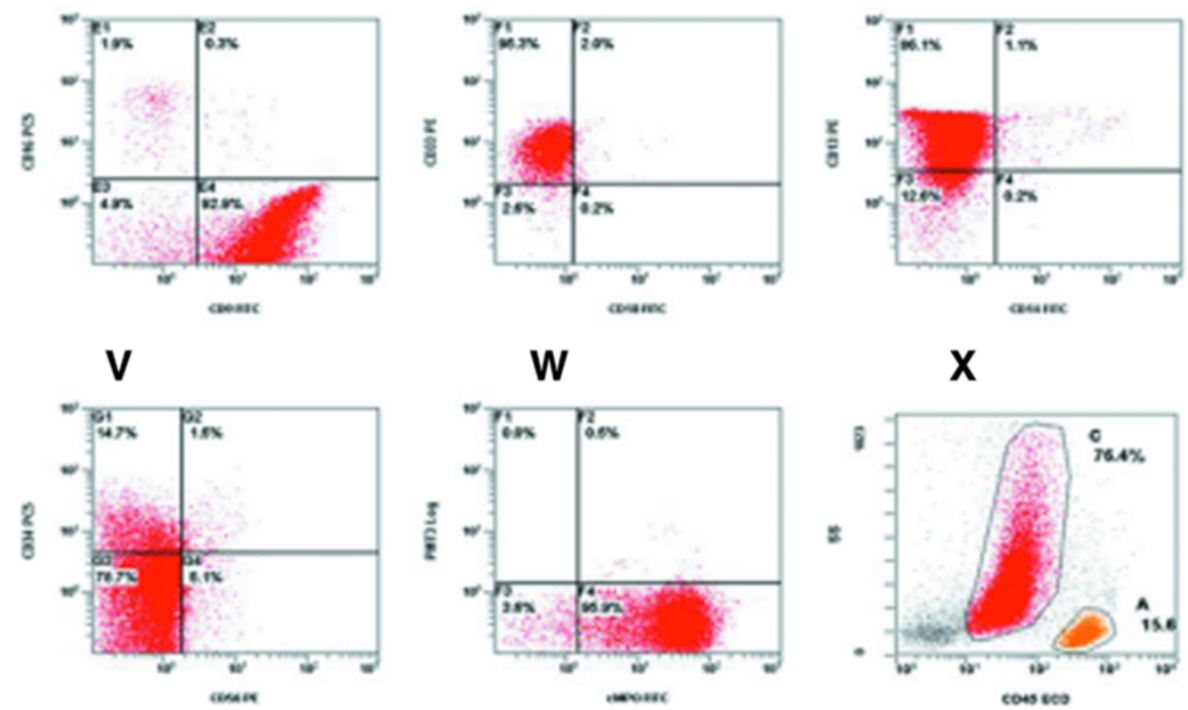

Figure 2 FCM of AML-M2/M3 patients. M-Q: Immunophenotype of Case 2 as measured by FCM. R-W: Immunophenotype of Case 3. X: Immunophenotype of Case 5. Bone marrow karyocytes contained a group of abnormal cells (group C, red) accounting for $76.4 \%$ of the total.

by flow cytometry, and results of cytogenetic analysis for all seven case patients are summarized in Tables 1 , 2,3 , and 4 . The majority of cells were positive for antigens of the myeloid lineage and negative for antigens of the lymphocytic lineage.

\section{Chemotherapy}

Five of the six cases were treated by standard chemotherapy $[17,18]$ (daunorubicin + cytarabine, DA) combined with all-trans retinoic acid (ATRA) or arsenic trioxide (ATO). The other case (case 6) was first treated with ATRA, compound realgar, and natural indigo tablets (CRINT), and then given reduced dose DA [19]. After the initial treatment, 5 cases achieved complete remission (CR), including one case with recurrence after three months that transformed into AML-M2 (Case 6). The average time to achieve $\mathrm{CR}$ was 37 days. Two cases did not achieved remission (including one death). After stem cell transplantation, patients with AML-M2/M3 might have prolonged event-free survival (Table 5).

\section{Results}

When newly diagnosis, $85.7 \%$ of case patients (6/7) had fever, $71.4 \%$ (5/7) had sternum pressing pain, hemorrhagic symptoms, and anemia, 28.6\% (2/7) presented with hepatomegaly or splenomegaly, $100 \%$ had leukocytosis 


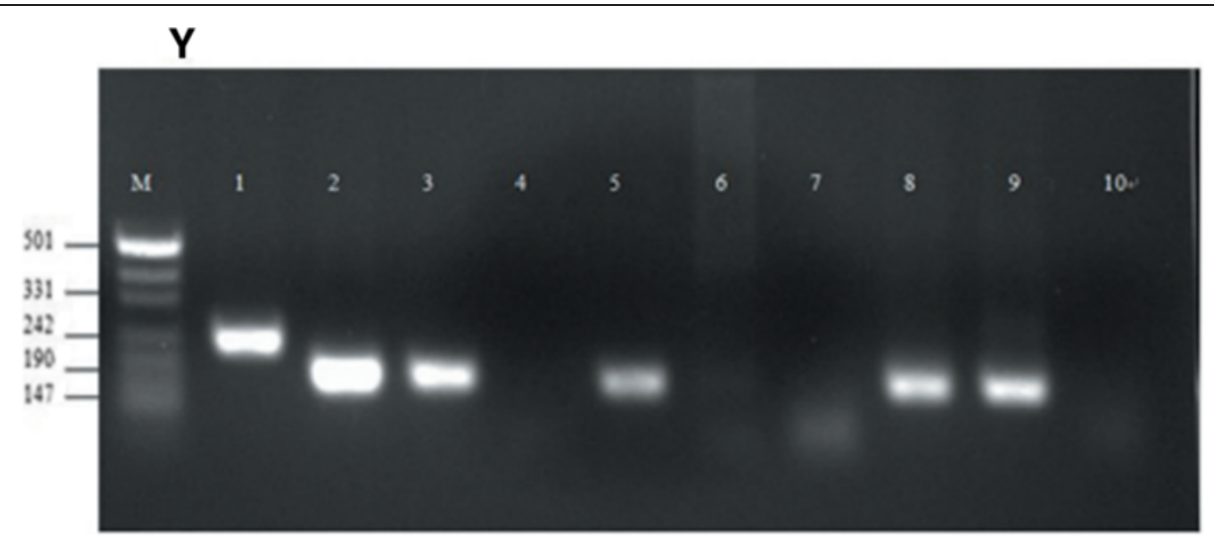

Figure 3 Y: Nested RT-PCR for Case 7: M: marker. 1 - 7: PML/RARa fusion gene. 1: mutation, type S positive control; 2: patient type S PCR products; 3: type S positive control; 4: healthy control, type S PCR products; 5 : type L positive control; 6: patient type L PCR products; 7: healthy control, type L PCR products. 8-10: AML1/ETO fusion gene; 8: positive control; 9: patient PCR products; 10: healthy control PCR products.

or leukopenia, and thrombocytopenia, $28.6 \%$ showed reduced hemocytes (all lineages), 100\% had coagulation abnormalities, and $85.7 \%$ had elevated serum LDH. All patients had $>20 \%$ myeloblasts and $>20 \%$ abnormal promyelocytes, of which $71.4 \%$ had $>30 \%$ BM myeloblasts and abnormal promyelocytes. All six patients tested were MPO (+). Six patients were PML/ RARa positive and two of these patients harbored both the AML1/ETO and PML/RARa fusion genes. Immunophenotyping (Table 3 ) showed that BM and PB cells expressed antigens of the myeloid lineage, including CD9, CD11b, CD13, CD15, CD33, CD34, CD38, CD45, CD56, CD64, CD117, HLA-DR, and cMPO.

\section{Discussion}

The FAB classification scheme (1976) divided AML into subtypes based on the morphology of BM or PB cells, while the current World Health Organization (WHO) classification system incorporates morphology, cytogenetics, molecular genetics, and immunological markers for the diagnosis of AML subtypes [2,5,8]. Acute myeloid leukemia is divided into two subtypes with different treatments and prognoses, AML-M2 and APL (AML-M3), depending on the magnitude of the increase in myeloblasts or abnormal promyelocytes [3-5]. Here, we provide evidence for a mixed phenotype (AML-M2/M3) with the characteristics of both AML-M2 and AML-M3. The clonal and temporal relationship between APL and the secondary AML subtype are usually obscure [20-23]. In fact, a chimeric M3:M2 case of acute promyelocytic leukemia was recently presented [24].

According to the diagnostic criteria for AML, AML-M2 is characterized by significantly increased myeloblasts, while AML-M3 is associated with abnormal promyelocytes. However, six of our cases meet the diagnostic criteria for both AML-M2 ( $>30 \%$ myeloblasts) and AML-M3 ( $>30 \%$ abnormal promyelocytes). We also observed two patients with both the AML1/ETO and the PML/RAR $\alpha$ fusion gene. Such cases cannot be classified as AML-M2 or AML-M3, so we suggest a new subtype of AML, AMLM2/M3 [2,5,8,15-17].

The diagnosis of AML-M2/M3 requires all available information, including morphology, cytochemistry, immunophenotyping, genetics, and clinical features $[2,8]$. In particular, BM cell morphology and the presence of the PML/RARa and/or AML1/ETO fusion gene define this subtype, while the immunophenotype is not sufficiently distinct from previously defined subtypes for diagnosis.

In $\mathrm{BM}$ and $\mathrm{PB}$ smears, all cases showed a simultaneous increase in myeloblasts and abnormal promyelocytes. Some promyelocytes contained dust-like or sparsely distributed granules. Promyelocyte nuclei were kidney-shape or even bi-lobed with inconspicuous to prominent nucleoli. Some promyelocytes also contained Aure rods.

Table 1 AML-M2/M3 case profiles

\begin{tabular}{|c|c|c|c|c|c|c|c|c|}
\hline Variable & Case 1 & Case 2 & Case 3 & Case 4 & Case 5 & Case 6 & Case 7 & $\%(7 / 7)$ \\
\hline Aex/age & Male/10 & Male/57 & Female/57 & Male/32 & Male/76 & Male/8 & Female/30 & \\
\hline Fever & $38.5^{\circ} \mathrm{C}$ & $37.8^{\circ} \mathrm{C}$ & $37.8^{\circ} \mathrm{C}$ & $38^{\circ} \mathrm{C}$ & $36.8^{\circ} \mathrm{C}$ & $38.4^{\circ} \mathrm{C}$ & $38^{\circ} \mathrm{C}$ & $85.7(6 / 7)$ \\
\hline Sternum pressing pain & + & \pm & + & + & - & + & + & $71.4(5 / 7)$ \\
\hline Hepatomegaly or splenomegaly & + & - & + & - & - & - & - & $28.6(2 / 7)$ \\
\hline Hemorrhagic symptoms & + & - & + & + & + & - & + & $71.4(5 / 7)$ \\
\hline
\end{tabular}

+ , positive, showed the symptoms; -, negative, no such symptom; \pm , the symptoms were not prominent. 
Table 2 Laboratory features of 7 patients with AML-M2/M3

\begin{tabular}{|c|c|c|c|c|c|c|c|c|c|}
\hline Variable & Case 1 & Case 2 & Case 3 & Case 4 & Case 5 & Case 6 & Case 7 & $\begin{array}{l}\text { Higher than } \\
\text { Normal, n (\%) }\end{array}$ & $\begin{array}{l}\text { Lower than } \\
\text { Normal, } \mathrm{n}(\%)\end{array}$ \\
\hline$\overline{W B C}\left(\times 10^{9} / \mathrm{L}\right)$ & 112 & 0.8 & 119.1 & 60.9 & 1.5 & 17.8 & 10.1 & $5(71.4)$ & $2(28.6)$ \\
\hline $\operatorname{RBC}\left(\times 10^{12} / \mathrm{L}\right)$ & 4.1 & 1.6 & 3.3 & 2.6 & 2.2 & 3.8 & 3.56 & $0(0.0)$ & $2(28.6)$ \\
\hline $\mathrm{HB}(\mathrm{g} / \mathrm{L})$ & 122 & 57 & 93 & 82 & 77 & 105 & 119 & $0(0.0)$ & $6(85.7)$ \\
\hline Platelets $\left(\times 10^{9} / \mathrm{L}\right)$ & 75 & 18 & 18 & 26 & 52 & 65 & 39 & $0(0.0)$ & $7(100)$ \\
\hline LDH (U/L) & 294 & 192 & 706 & 383 & 364 & 937 & 1037 & $6(85.7)$ & $1(14.6)$ \\
\hline PT (sec) & 15.8 & 15.1 & 25.2 & 15.9 & 13.5 & 13.3 & 13.6 & $4(57.1)$ & $0(0.0)$ \\
\hline Fibrinogen (g/L) & 1.4 & 5.1 & 0.6 & 2 & 3.6 & 3.1 & 4.23 & $2(28.6)$ & $2(28.6)$ \\
\hline D-dimer (ng/ml) & $>10000$ & 1249 & 3607 & 3310 & 821 & - & 881 & $6(85.7)$ & $0(0.0)$ \\
\hline BM Myeloblasts & $62 \%$ & $47.50 \%$ & $39.50 \%$ & $85 \%$ & $42.50 \%$ & $17 \%$ & $49 \%$ & $7(100)$ & $0(0.0)$ \\
\hline $\begin{array}{l}\text { BM abnormal } \\
\text { promyelocytes }\end{array}$ & $38 \%$ & $35.50 \%$ & $49.50 \%$ & $11.50 \%$ & $30 \%$ & $49.50 \%$ & $29 \%$ & $7(100)$ & $0(0.0)$ \\
\hline PB Myeloblasts & $61 \%$ & 0 & $47 \%$ & $67 \%$ & $1 \%$ & $36 \%$ & $14 \%$ & $5(71.4)$ & $0(0.0)$ \\
\hline $\begin{array}{l}\text { PB abnormal } \\
\text { promyelocytes }\end{array}$ & $17 \%$ & 0 & $50 \%$ & $24 \%$ & 0 & $28 \%$ & $13 \%$ & $5(71.4)$ & $0(0.0)$ \\
\hline MPO of BM smears & $\begin{array}{l}62 \% \text { strongly } \\
\text { positive }\end{array}$ & $\begin{array}{l}94 \% \text { strongly } \\
\text { positive }\end{array}$ & 99\% positive & $\begin{array}{l}>90 \% \text { strongly } \\
\text { positive }\end{array}$ & 99\% positive & - & 95\% positive & & \\
\hline $\begin{array}{l}\text { AS-DCE of BM } \\
\text { smears }\end{array}$ & $48 \%$ positive & $23 \%$ positive & 70\% positive & 19\% positive & $>90 \%$ positive & - & $50 \%$ positive & & \\
\hline NSE of BM smears & - & $\begin{array}{l}8 \% \text { weakly } \\
\text { positive }\end{array}$ & $<20 \%$ positive & $\begin{array}{l}>90 \% \text { strongly } \\
\text { positive }\end{array}$ & - & - & - & & \\
\hline
\end{tabular}

WBC, white blood cell count in peripheral blood; RBC, red blood cell count; HB, hemoglobin; LDH, lactate dehydrogenase; PT, prothrombin time; APTT, activated partial thromboplastin time; BM, bone marrow; PB, peripheral blood; MPO, myeloperoxidase; AS-DCE, naphthol AS-D chloroacetate esterase; NSE, non-specific esterase (or alpha-naphthol acetate esterase, a-NAE); -, no results available. 
Table 3 Immunophenotype of 7 patients with AML-M2/M3 by FCM

\begin{tabular}{|c|c|c|c|c|c|c|c|c|c|c|c|c|c|c|}
\hline No. & \multicolumn{2}{|c|}{ CD45(blast) } & CD9 & CD13 & CD33 & CD34 & CMPO & CD117 & HLA-DR & CD11b & CD15 & CD38 & CD56 & D64 \\
\hline Case 1 & \multicolumn{2}{|l|}{81.1} & 47.5 & 32.7 & 46.9 & - & - & - & - & - & - & 41.0 & - & - \\
\hline Case 2 & \multicolumn{2}{|l|}{69.0} & - & 47.0 & 62.9 & 78.1 & - & 55.1 & 85.4 & - & - & - & - & - \\
\hline Case 3 & \multicolumn{2}{|l|}{80.3} & 93.2 & 87.2 & 97.3 & 16.2 & 96.4 & - & - & - & - & - & - & - \\
\hline Case 4 & \multicolumn{2}{|l|}{83.7} & 92.5 & - & 97.0 & - & 98.9 & 16.4 & - & 12.7 & - & - & - & 86.7 \\
\hline Case 5 & \multicolumn{2}{|l|}{76.4} & - & 30.9 & 95.5 & - & 78.4 & 78.4 & - & - & 11.6 & - & 96.5 & 16.9 \\
\hline Case 6 & \multicolumn{2}{|l|}{44.9} & \multicolumn{12}{|c|}{ CD34/HLA-DR 29.6\%, CD15 6.5\%, CD14/CD11b 0.2\%, HLA-DR/CD13 3.5\% } \\
\hline \multirow{2}{*}{ Case 7} & \multirow{2}{*}{84.5} & 36.2 & - & 90.8 & 82.6 & 62.3 & 97.8 & 88.0 & 85.9 & 13.5 & 40.3 & - & 12.4 & 7.9 \\
\hline & & 48.3 & - & 94.9 & 83.0 & - & 98.9 & 43.8 & 35.0 & 46.6 & 95.3 & - & 26.1 & 70.4 \\
\hline
\end{tabular}

- , these antibodies were expressed in less than $10 \%$ of cells.

These morphological characteristics are distinct from the typical abnormal promyelocytic cells observed in AML-M3 [1-3].

Immunophenotyping showed that the SSCs expressed CD9, CD11b, CD13, CD15, CD33, CD34, CD38, CD45, CD56, CD64, CD117, and HLA-DR, antigens characteristic of both AML-M2 and AML-M3. Three cases expressed BM cells strongly positive for CD9 and four cases exhibited cells strongly positive for CD13 and CD33. Two of 6 cases exhibited cells with CD117 expression. In addition, CD34, cMPO, CD117, HLA-DR, CD11b, CD15, CD38, CD56, and CD64 were expressed in some cases. However, it is difficult to distinguished AML-M2 from AML-M3 according to immunophenotype [25-27].

It is uncertain whether the two cases with both fusion genes harbor two genetic rearrangements within the same clone or two independent clones with different rearrangements. Unfortunately, as this was a retrospective study, no further analysis was possible and there was no information on how the various FACS and molecular assays were performed. Further studies are needed to examine the frequency of this double genetic rearrangement in AML-M2/M3.

Many of the clinical characteristics of AML-M2/M3 are common to other subtypes of leukemia, including anemia, fever, hemorrhage, and infiltration. However, this group of patients was prone to DIC, cerebral hemorrhage, and other serious complications, with high mortality rates. Moreover, patients showed a trend for recurrence and transformation into AML-M2 [3,4]. Although some clinical procedures including transplantation of stem cell has been proposed in the present investigation, the suggestion was preliminary, not original and might not be general for all similar cases. Anyhow, we analyzed the treatment effects of ATRA, ATO, or CRINT combined with the DA regimen on seven patients with AML-M2/M3, whose clinical and laboratory features were analyzed scientifically and the data revealed that there were elevated myeloblasts and abnormal promyelocytes. Because up to now, there has been no uncontested criterion for the FAB sub-classification of AML, analyzing particular cases of AML without scientific genaralization of considered particular cases still is of some significance. Thus, it remains to be investigated in FAB sub-classification of AML and its clinical treatment. In addition, further studies are needed to examine the frequency of this double genetic rearrangement in AML-M2/M3.

At present, there are no guidelines for the treatment of this new subtype of AML. All of the patients were treated with ATRA, ATO, or CRINT combined with the DA regimen and five achieved complete temporary remission. Our initial observations suggest that hematopoietic stem cell transplantation may be beneficial for long-term survival. Therefore, the significance of the present study was that the patients with AML could be treated with ATRA, ATO, or CRINT combined with the DA regimen, and hematopoietic stem cell transplantation might be beneficial for long-term survival, possibly providing data for the guidelines for the FAB sub-classification and treatment of this new subtype of AML.

In the present study, we identified a novel entity of AML according to FAB classification and examined its clinical characteristics. Although the "gray-zone" entity

Table 4 Genetics features of 7 patients with AML-M2/M3

\begin{tabular}{lllllllll}
\hline Variable & & & & & & & & Total \\
& Case 1 & Case 2 & Case 3 & Case 4 & Case 5 & Case 6 & Case7 & + \\
\hline PML-RARa & $+/ S$ & - & $+/ S$ & $+/ S \& L$ & $+/ S$ & $+/ S$ & $+/ S$ & 5 \\
ETO & non & non & non & non & non & + & + & 1 \\
BCR-ABL & - & + & - & non & non & - & non & 1 \\
\hline
\end{tabular}

S, short type of PML-RARa; L, long type of PML-RARa; non, not examined. 
Table 5 Follow-up of 7 patients with AML-M2/M3 until 30th june, 2012

\begin{tabular}{lllll}
\hline & $\begin{array}{l}\text { Chemotherapy treatment } \\
\text { In our deparmett }\end{array}$ & $\begin{array}{l}\text { Subsequent } \\
\text { Treatment }\end{array}$ & $\begin{array}{l}\text { Time* } \\
\text { (days, d) }\end{array}$ & Final diagnosis \\
\hline Case 1 & 3 cycles & allo-SCT** & $1630 d$ & CR \\
Case 2 & 4 cycles & auto-SCT & $1492 \mathrm{~d}$ & CR \\
Case 3 & 1 cycle & - & $3 d$ & Death \\
Case 4 & 5 cycles & allo-SCT & $766 d$ & CR \\
Case 5 & 1 cycle & - & $>29 d$ & Non-remission, lost at follow-up \\
Case 6 & 4 cycles & - & $467 d$ & Recurrence, transformed into AMLM2 \\
Case 7 & 1 cycle & - & $53 d$ & CR \\
\hline
\end{tabular}

allo-SCT, allogeneic stem cell transplantation; auto-SCT: autologous stem cell transplantation.

*closing date: 30 June, 2012.

** the patient had the allo-SCT in another hospital.

of each of the FAB sub-classification has been recognized since the first proposal of FAB classification in 1976, unfortunately, this issue was not endowed with clear solution. Later, in a "proposed revised criteria for the classification of AML" by the FAB cooperative group in 1985 [28], the potential fermentation concerning discrimination between M2 and M3 has been asserted. The group noted that M2 was diagnosed when mature myeloid cells were over $10 \%$, even though "few" promyelocytes or later cells were present, indicating that M2 does not contain cases with "massive" promyelocytes. Therefore, according to the revised FAB criteria, the presented cases were not totally consistent with M2. In contrast, blasts percentage $>30 \%$ did not exclude M3 diagnosis. Indeed, myeloblasts occupy $>30 \%$ in about $10 \%$ of M3 cases [29]. Microscopic features of promyelocytes in the presented cases including sparse granules and bilobed nucleus were characteristics of AML M3 variant. Thus, we regarded the cases as AML-M2/M3, which remains to be further explored. Anyhow, the present investigation added new information for the analysis of AML$\mathrm{M} 2 / \mathrm{M} 3$.

In conclusion, the clinical and laboratory features of seven patients with AML-M2/M3 are demonstrated in the present study, providing information on the FAB sub-classification.

\section{Competing interests}

The authors declare that they have no competing interests.

\section{Authors' contributions}

GLH \& CYW provided the study concept and design; GLH wrote the manuscript; CYW helped write and revise of the manuscript; QEL found out and observed the phenomenon of morphology; HT helped write and revise of the manuscript; FXC, provided the clinical information of the child patients; $\mathrm{HZQ}$ provided the clinical information of the adult patients; BDY \& LXZ performed the examination; ZRH \& LD collected data, analyzed and interpreted data; and all authors reviewed and provided final approval of the manuscript.

\section{Acknowledgements}

No any forms of grants or equipment and drugs are received and support for this work. First of all, the authors would like thank Key Clincal Disciplines of Guangdong Province (20111219). The authors would also like to thank the patients and the following doctors working in Department of Hematology in the First Affiliated Hospital of Guangzhou Medical University, Guangzhou, China: Haiming Li, Sida Peng, Yaya Wang, Jingren Lin, Tiantian Xiao, Haibin Huang, et al. The authors would also like to thank Department of Hematology, Department of Pediatrics and State Key Laboratory of Respiratory Disease of the hospital, which provided all the data we needed.

\section{Author details}

'Department of Hematology, The First Affiliated Hospital of Guangzhou Medical University, No. 1 Kangda Road, Haizhu District, 510000 Guangzhou, China. ${ }^{2}$ Department of Pediatrics, The First Affiliated Hospital of Guangzhou Medical University, Kangda Road, Guangzhou, China. ${ }^{3}$ State Key Laboratory of Respiratory Disease, The First Affiliated Hospital of Guangzhou Medical University, Kangda Road, Guangzhou, China.

Received: 6 June 2013 Accepted: 22 October 2014

Published online: 31 December 2014

\section{References}

1. Jaffe ES, Harris NL, Stein H, Vardiman JW: World Health Organization Classification of Tumours. Pathology and Genetics of Tumours of Hematopoietic and Lymphoid Tissues. Lyon, France: IARC; 2001:75-87.

2. Swerdlow SH, Campo E, Harris NL, Jaffe ES, Pileri SA, Stein H, Thiele J, Vardiman JW: WHO Classification of Tumours of Hematopoietic and Lymphoid Tissues. Lyon, France: IARC; 2008:100-117.

3. Estey E, Dohner H: Acute myeloid leukemia. Lancet 2006, 368(9550):1894-1907.

4. Lowenberg B, Downing JR, Burnett A: Acute myeloid leukemia. N Engl Med 1999, 341(14):1051-1062.

5. Bennett JM, Catovsky D, Daniel MT, Flandrin G, Galton DA, Gralnick HR, Sultan C: Proposed revised criteria for the classification of acute myeloid leukemia. A report of the French-American-British Cooperative Group. Ann Intern Med 1985, 103(4):620-625.

6. De Jonge HJ, Huls G, de Bont ES: Gene expression profiling in acute myeloid leukemia. Neth J of Med 2011, 69(4):167-176.

7. Vardiman JW, Harris NL, Brunning RD: The World Health Organization (WHO) classification of the myeloid neoplasms. Blood 2002, 100(7):2292-2302.

8. Vardiman JW, Thiele J, Arber DA, Brunning RD, Borowitz MJ, Porwit A, Harris NL, Le Beau MM, Hellström-Lindberg E, Tefferi A, Bloomfield CD: The 2008 revision of the World Health Organization (WHO) classification of myeloid neoplasms and acute leukemia: rationale and important changes. Blood 2009, 114:937-951.

9. Kelly LM, Gilliland DG: Genetics of myeloid leukemia. Annu Rev Genomics Hum Genet 2002, 3:179-198.

10. Stavroyianni $N$, Kalmantis T, Yataganas $X$ : Simultaneous PML/RAR alpha and AML 1/ETO gene rearrangements in a patient with acute myeloid leukemia. Leukemia 1999, 13(08):294-295.

11. Schlenk RF, Dohner K, Krauter J, Fröhling S, Corbacioglu A, Bullinger L, Habdank M, Späth D, Morgan M, Benner A, Schlegelberger B, Heil G, Ganser A, Döhner $\mathrm{H}$ : Mutations and treatment outcome in cytogenetically normal acute myeloid leukemia. N Engl J Med 2008, 358:1909-1918. 
12. Arber DA, Stein AS, Carter NH, Ikle D, Forman SJ, Slovak ML: Prognostic impact of acute myeloid leukemia classification. Importance of detection of recurring cytogenetic abnormalities and multilineage dysplasia on survival. Am J Clin Pathol 2003, 119:672-680.

13. Haferlach T, Schoch C, Loffler H, Gassmann W, Kern W, Schnittger S, Fonatsch C, Ludwig WD, Wuchter C, Schlegelberger B, Staib P, Reichle A Kubica U, Eimermacher H, Balleisen L, Grüneisen A, Haase D, Aul C, Karow J, Lengfelder E, Wörmann B, Heinecke A, Sauerland MC, Büchner T,

Hiddemann W: Morphologic dysplasia in de novo acute myeloid leukemia (AML) is related to unfavorable cytogenetics but has no independent prognostic relevance under the conditions of intensive induction therapy: results of a multiparameter analysis from the German AML Cooperative Group studies. J Clin Oncol 2003, 21:256-265.

14. Pileri SA, Ascani S, Cox MC, Campidelli C, Bacci F, Piccioli M, Piccaluga PP, Agostinelli C, Asioli S, Novero D, Bisceglia M, Ponzoni M, Gentile A, Rinaldi P, Franco V, Vincelli D, Pileri A Jr, Gasbarra R, Falini B, Zinzani PL, Baccarani M: Myeloid sarcoma: clinico-pathologic, phenotypic and cytogenetic analysis of 92 adult patients. Leukemia 2007, 21:340-350.

15. Matutes E, Morilla R, Farahat N, Carbonell F, Swansbury J, Dyer M, Catovsky D: Definition of acute biphenotypic leukemia. Hematological 1997, 82:64-66.

16. Hanson CA, Abaza M, Sheldon S, Ross CW, Schnitzer B, Stoolman LM: Acute biphenotypic leukemia: immunophenotypic and cytogenetic analysis. Br J Haematol 1993, 84:49-60.

17. Sulak LE, Clare CN, Morale BA, Hansen KL, Montiel MM: Biphenotypic acute leukemia in adults. Am J Clin Pathol 1990, 94:54-58.

18. Mirabelli P, Scalia G, Pascariello C, D'Alessio F, Mariotti E, Di Noto R, George TC, Kong R, Venkatachalam V, Basiji D, Del Vecchio L: ImageStream promyelocytic leukemia protein immunolocalization: in search of promyelocytic leukemia cells. Cytometry 2012, 81(3):232-237.

19. Shen $Y$, Zhu YM, Fan X, Shi JY, Wang QR, Yan XJ, Gu ZH, Wang YY, Chen B, Jiang CL, Yan H, Chen FF, Chen HM, Chen Z, Jin J, Chen SJ: Gene mutation patterns and their prognostic impact in a cohort of 1185 patients with acute myeloid leukemia. Blood 2011, 118(20):5593-5603.

20. Desangles F, Vilain E, Arborio M, De Revel T, Flandrin G: t(15;17) hypergranular acute promyelocytic leukemia (M3) developing into a t $(3 ; 6)$ M3 without $\mathrm{t}(15 ; 17)$ at relapse. Leuk Lymphoma 1995, 19:185-188.

21. Hatzis T, Standen GR, Howell RT, Savill C, Wagstaff M, Scott GL: Acute promyelocytic leukemia (M3): relapse with acute myeloblastic leukemia (M2) and dic(5;17)(q11;p11). Am J Hematol 1995, 48:40-44

22. Todisco E, Testi AM, Avvisati G, Moleti ML, Cedrone M, Cimino G, Mancini F, Amadori S, Mandelli F: Therapy-related acute myelomonocytic leukemia following successful treatment for acute promyelocytic leukemia. Leukemia 1995, 9:1583-1585.

23. Jubashi T, Nagai K, Miyazaki Y, Nakamura H, Matsuo T, Kuriyama K, Tomonaga M: A unique case of acute promyelocytic leukemia (M3) developing into acute myeloblastic leukemia (M1) with $t(7 ; 21)$ at relapse. Br J Haematol 1993, 83:665-668.

24. Bonomi $\mathrm{R}$, Giordano $\mathrm{H}$, del Pilar Moreno M, Bodega E, Landoni Al, Gallagher $\mathrm{R}$, del Rosario Uriarte M: Simultaneous PML/RARalpha and AML1/ETO expression with $\mathrm{t}(15 ; 17)$ at onset and relapse with only $\mathrm{t}(8 ; 21)$ in an acute promyelocytic leukemia patient. Cancer Genet Cytogenet 2000, 123(1):41-3

25. National Comprehensive Cancer Network Inc. NCCN: Clinical Practice Guidelines in Oncology. Acute Myeloid Leukemia [EB/OL]. [www.ncen.org. 2011; version 2: 1-8]

26. Nguyen DT, Diamond LW, Braylan RC: Flow cytometry in hematopathology: a visual approach to data analysis and interpretation. Humana Press Inc 2003, 143-145:188-191.

27. Béné MC, Porwit A: Acute leukemias of ambiguous lineage. Semin Diagn Pathol 2012, 29(1):12-18.

28. Lithotripsy. Health and Public Policy Committee, American College of Physicians. Ann Intern Med 1985; 103(4): 626-9.

29. Stanley M: Adult Leukemia 2. Boston. Martinus Nijhoff Publishers 1985, 29(1):147.

\section{Submit your next manuscript to BioMed Central and take full advantage of:}

- Convenient online submission

- Thorough peer review

- No space constraints or color figure charges

- Immediate publication on acceptance

- Inclusion in PubMed, CAS, Scopus and Google Scholar

- Research which is freely available for redistribution

Submit your manuscript at www.biomedcentral.com/submit 